\title{
Revealing Biocontrol prospective of a few Bacterial Isolates segregated from tea rhizosphere of Barak Valley, Assam, India against a fungal pathogen.
}

\author{
${ }^{1}$ Pranab Mazumder, ${ }^{*}$ Mrinal Kanti Bhattacharjee and ${ }^{2}$ Prof .G.D.Sharma \\ *l Biotechnology Department, Silchar, Assam University. \\ ${ }^{2}$ Vice Chancellor Bilaspur University,
}

\begin{abstract}
In this paper an inquiry was conceded away for segregation of some microorganisms from rhizosphere zone of tea from tea growing regions of Barak valley, Assam; India. The isolates were secluded from tea rhizosphere of Toklai varieties (TV17, 20, 23) from some tea estates of Barak valley. Five isolates were recognized up to their genre stage on the foundation of their morphological and biochemical distinctiveness and finally the appraisal of disorganize possibility against fungi Fusarium oxysporum was ascertained and spelled out.
\end{abstract}

Key words: ascertained, disorganize possibility, genus, rhizosphere, Toklai variety.

\section{Introduction:}

In this respect an endeavor was undertaken to isolate some strains of bacteria of Bacillus genera from the "rhizosphere" of tea plants from the Barak valley (South Assam) province. The isolates were separated in their own medium ,also fungi Fusarium oxysporum was taken from the Department of Ecology of Assam university and finally all the obtained bacterial isolates were tested against the fungi for antagonistic action and ultimately the performance was tested and the mechanism by which the bacteria shows this action was found out. Not only this, the biochemical mannerisms and the external appearances of the bacterial isolates were discussed and finally the results were tabulated. The research was carried out in some tea gardens of Barak Valley, Assam, India. The following tea varieties were used and taken into deliberation were: TV17, 20 and 23 (Toklai Varieties).As many strains of same bacteria genus were isolated and out of that best strains were taken into consideration.

\section{Materials and Methods:}

Soil sections from deepness of $0-25 \mathrm{cms}$ were assembled haphazardly from some tea estates in the year 2009- 2010, from the TV17, 20 and 23 Toklai varieties of tea.

\section{Isolation of strains from tea rhizosphere:}

The bacteria of Bacillus genus was secluded on a tailored medium of Travers et al. (1987) [1] as described in by Teenakoon (2007) [2].Lastly the pure cultures of the same isolates were attained on the identical medium by recurred staining.

\section{Isolation of fungi (Fusarium oxysporum):}

Although the fungi was taken from the Ecology department, but the way utilized for its isolation and listing of fungi Fusarium oxysporum from infected wilt leaves of some infected plants in Martin's agar medium [3] source [4]. The colonies attained on the medium was put side by side with the normal results as described by[5].

Characteristics of the morphological traits of the bacterial isolates:

The isolates acquired on the above following medium for Bacillus were carried out for the morphology of their colony, form of their cells, of their motility and dimension of the isolates as per the usual schemes portrayed by [6]. The test for the motility and attributes of their culture was additionally authenticated by carrying out by the usual process delineated by [6].

By following [6] procedures Gram staining was done.

Characteristics of the biochemical traits of the isolates:

The biochemical sorting of the isolates was done with a slight adjustment by setting the temperature for incubation at room temperature as a substitute of $37^{\circ} \mathrm{C}$ mentioned in the customary protocols, by pursuing the course of actions outlined by [6]. The trials performed are specified under: 
(i).Gram staining. (ii).Catalase Test- (iii).Test for Reduction for nitrate -(IV).Test for Hydrolysis of starch (v). Test for Urease activity (VI). Test for Oxidase activity (vii). Test for Gelatin liquefaction. All the above tests by [6].

\section{Biocontrol prospective of the isolates against fungi:}

All the isolates isolated from tea rhizosphere of tea growing regions of Barak Valley, Assam, India were examined in vitro for their bio management role, using the double inoculation method as described by [7] against the fungal pathogen Fusarium oxysporum. The percent inhibition was computed; $\mathrm{PI}=\mathrm{C}-\mathrm{T} / \mathrm{C}$ in $\mathrm{cms}, \mathrm{C}$ is in the absence of antagonist the growth of test pathogen in $\mathrm{cm}, \mathrm{T}$ - is the test pathogen in presence of antagonist strain also in cm.The above formula is obtained from the source Teenakoon (2007) [2].

\section{Methods of pathogen inhibition by the isolates:}

There are a variety of methods by which organisms show anatagonisms. Two methods are given below as been done by the researcher:

\section{Exhibition of HCN Production by the isolates:}

This method was adopted as described by Wei et al. (1991) [8] which have been elucidated by Teenakoon (2007) [2] in his research on the same field. In the germ-free Petri plates, Trypticase Soy Agar medium adjusted with glycine $(4.4 \mathrm{~g} / \mathrm{l})$ was dispensed.

On the Petri plates containing the medium the isolate having the utmost hostile activity against the pathogenic creature was streaked and then covered with filter padding.

Then every plate that were wrapped with the filter paddings were supplied with picric acid solution and after that, the plates were closed nicely with parafilm, in order to avoid the loss of gaseous metabolites made by the antagonists and also to authorize the chemical reaction with picric acid present in the filter padding. There after the plates were incubated at room temperature for about seven days [8] and observed for changes [2].

\section{Manufacture of Volatile metabolites:}

Also the bacterial isolates were appraised for the making up of volatile metabolites by which they restrain the mycelium growth of fungal colonies. It was resolved by usual Mariano method (1993) [9] the methodology of [9] has been adopted from [10]. The calculation for the volatile metabolites was not carried out.

\section{Results: Morphological traits of the LA Isolates:}

\begin{tabular}{|l|l|l|l|l|l|}
\hline Sl. No. & isolates & Cell form & $\begin{array}{l}\text { Cell } \\
\text { measurement }\end{array}$ & $\begin{array}{l}\text { Colony } \\
\text { nature }\end{array}$ & motility \\
\hline 1 & LA1 & Rod & $1.2 \mu \mathrm{m}$ & white & Non motile \\
\hline 2 & LA2 & Rod & $1.5 \mu \mathrm{m}$ & white & Non motile \\
\hline 3 & LA3 & Rod & $1.5 \mu \mathrm{m}$ & white & Non motile \\
\hline 4 & LA4 & Rod & $1.0 \mu \mathrm{m}$ & white & Non motile \\
\hline 5 & LA5 & Rod & $1.7 \mu \mathrm{m}$ & white & Non motile \\
\hline
\end{tabular}

Biochemical traits of the LA (Luria Agar isolates) isolates:

\begin{tabular}{|l|l|l|l|l|l|l|l|l|}
\hline $\begin{array}{l}\text { Sl. } \\
\text { No. }\end{array}$ & Isolates & A & B & C & D & E & F & G \\
\hline 1 & LA1 & + & + & - & + & + & + & + \\
\hline 2 & LA2 & + & + & - & + & + & + & + \\
\hline 3 & LA3 & + & + & - & + & - & + & + \\
\hline 4 & LA4 & + & + & - & + & + & + & - \\
\hline 5 & LA5 & + & + & - & + & - & + & - \\
\hline
\end{tabular}

A. Gram staining test. B. Catalase C. Oxidase D. Starch hydrolysis E. Gelatin liquefaction F. Nitrate reduction G. Urease activity.

Result: _ means no result, + means modest result, ++ fine results.

Biocontrol action of the Isolates against Fusarium oxysporum: (ZOI-zone of inhibition) (best three isolates were taken for the tests)

\begin{tabular}{|l|l|l|l|l|}
\hline SI No. & Isolates & ZOI in cms & HCN production & $\begin{array}{l}\text { Volatile } \\
\text { metabolites }\end{array}$ \\
\hline 1. & LA2 & 3.2 & - & + \\
\hline 2. & LA3 & 3.6 & - & + \\
\hline
\end{tabular}




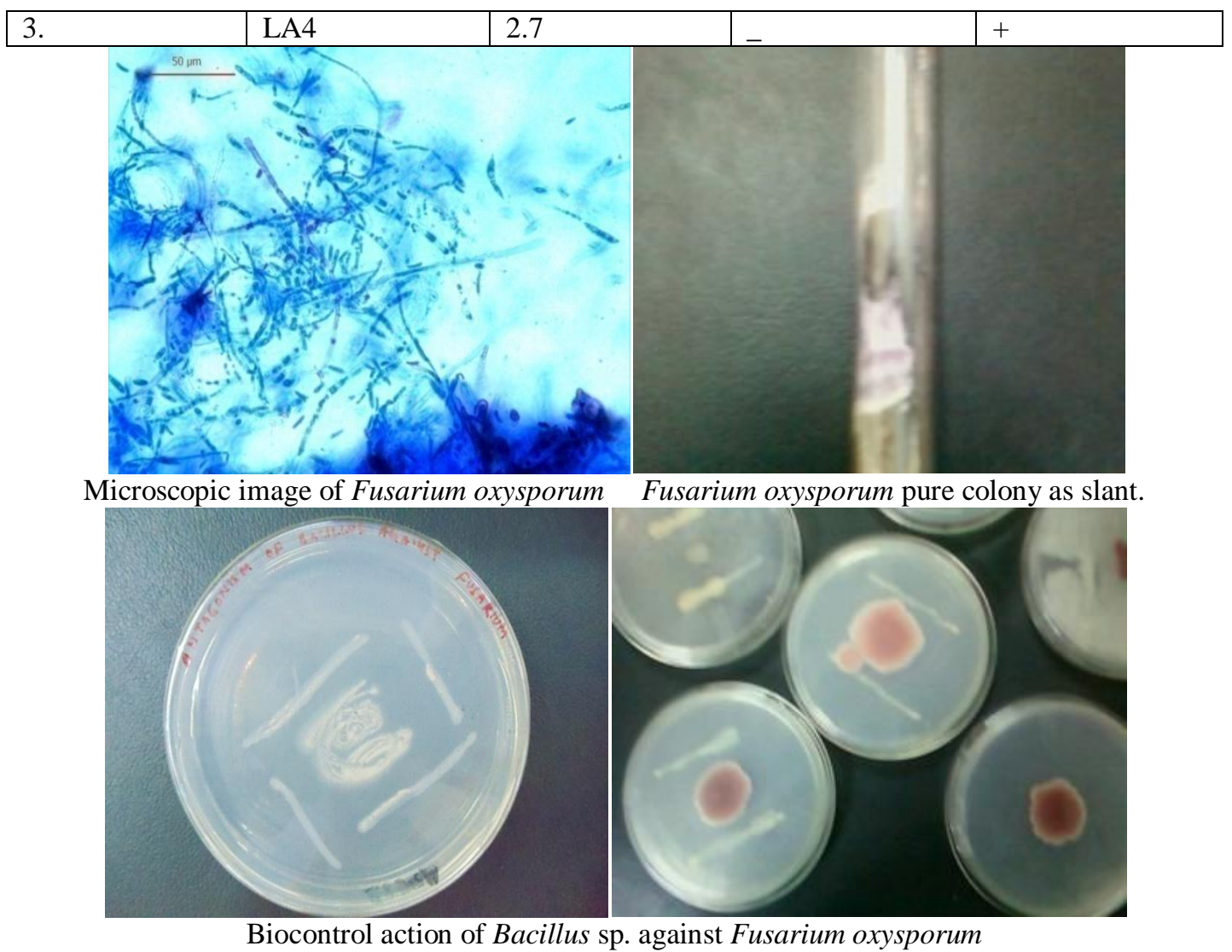

\section{Discussion:}

A total of 5 bacterial isolates were collected from the rhizosphere of tea plants of Southern Assam (Barak Valley), India, from the clonal of variety (Tocklai Varieties) TV17, 20 and 23 in the year 2009- 2010. Photos were taken by a digital camera, except the microscopic photo by Leicas microscopy done at Ecology Dept. of ecology in Assam University.

Isolates obtained on Luria agar medium, were white rod shaped with a size ranging between 1-1.7 $\mu \mathrm{m}$ and all the isolates were found non motile based on their motility tests.

The isolates obtained on LA (Luria agar medium) were Gram positive by nature, nitrate positive, catalase positive, oxidase negative, all were starch positive, strain number LA1,2 and4 showed gelatin liquefaction, , isolate LA1,LA2. And LA3 showed positive urease activity. On the basis of that it has been inferred that the possible isolates could be of the genus Bacillus by following the Bergey's Manual of Determinative Bacteriology [11].

The isolates were tested for hostile action against Fusarium oxysporum and showed encouraging reply. The biocontrol possibility of Bacillus against Fusarium oxysporum was found in accordance with the results obtained by Amini et al. (2012), [12] made in the paper of Australian Journal of crop science he has reported his findings on antagonistic activities shown by Bacillus as well as Pseudomonas against Fusarium oxysporum that causes wilting in chickpea and they also tested for production of $\mathrm{HCN}$ as well as volatile metabolites by the bacterial isolates against Fusarium oxysporum and found comparable outcomes.

\section{Conclusion:}

Five of the isolates of the genus Bacillus was checked for hostile action against fungi Fusarium oxysporum that is mainly believed as an agent that causes wilting in several plants. Although many works have been done earlier on this aspect of biocontrol role of Bacillus against Fusarium oxysporum, but here in this part of South Assam, India (Barak Valley) from tea rhizosphere is an exhilarating endeavor. Still many works further is needed to be carried out.

\section{Acknowledgement:}

I show my homage towards Prof. B.K.Datta, Head of the department of Ecology, Assam University, and Romila for providing me a strain of Fusarium .And the Department of Biotechnology, Assam University and Dr.Rout for her assistance in giving to use her Leicas Microscope. And isolate photographs were taken by (Nikon3100) digital camera. Also thanks P.L.K.Tenaakon whose work gave idea to me and all references works. 


\section{References:}

[1]. Travers, R.S., Martin, P.A.W. and Reichelderfer, C.F. (1987). Selective process of efficient isolation of soil Bacillus spp. Appl. Environ. Microbiol. 53:1263-1266.

[2]. Priyanthi.L.K.Teenakoon. (2007).Studies on Plant growth Promoting Microorganisms of Tea (camellia sinensis L. (o) Kuntze) Plants. Thesis submitted for partial fulfillment of the award of master degree in agricultural sciences in Agricultural microbiology. Department of agricultural Microbiology. College of Agriculture. University of Agricultural Sciences .Dharwad.

[3]. Martin, J. P. (1950). Use of acid, Rose Bengal and streptomycin in the plate method for estimating soil fungi. Soil Sci. 69: $214-232$.

[4]. Dubey, R.C. and D.K, Maheshwari. (2002).A Textbook of Practical Microbiology.S.Chand \& Co.Ltd, Ram Nagar, Newdelhi.pp.2192.

[5]. Gilman, J.C. (1957). A Manual of soil fungi.2 $2^{\text {nd }}$ ed. Lowa State College, Press. Amst, Iowa, USA. Pp: 450.

[6]. Cappuccino, J.G.and Sherman, N. (2005). Microbiology: A Laboratory Manual. $7^{\text {th }}$ edition. Pearson.Inc. and Darling Kindesley publishing, Inc.

[7]. Sakthivel, N.and. Gnanamanickam, S.S. (1987).Evaluation of Pseudomonas fluorescens for suppression of sheath rot disease and enhancement of grain yields in rice (Oryza sativa L.).Appl. Environ.Microbiol.pp.2056-2059.

[8]. Wei, G., Kloepper, J.W. and Tuzum, S. (1991).Induction of systematic resistance of Cucumber to Colletotrichum orbiculare by selected strains of plant growth promoting rhizobacteria.Phytopathol.81:1508-1512.

[9]. Mariano, R.L. (1993). Métodos de seleção in vitro para o control e microbiológico de patógenos de plantas. Revisão Anual de Patología de Plantas. 1:369-409.

[10]. V.Sanfuentes.,A.Gacitu,S.,P.Diaz,K.,C.Hernandez,J.,F.Valiente,C. and M.Uribe,M. (2009).Identification and Biological Characterization of Isolates with Activity Inhibitive Against Macrophomina phaseolina (Tassi) Goid. Chilean J. Agri. Research. 69(4): 526-533.

[11]. Holt,J.G.,Kreig,W.R.,sneath,P.H.A.,staley,J.T. and William ,S.T.(1994).Bergey’s manual of Determinative Bacteriology. Ninth edition.williams and Wilkinson. A. Waverly Company.

[12]. Amini, J., Karimi, K., Harighi, B.and Bahramnejad, B. (2012).Evaluation of Biocontrol Potential of Pseudomonas and Bacillus spp. against Fusarium wilt of chickpea. Australian J. Crop sci.6 (4):695-703. 